\title{
DIOS Y EL MAL EN KIERKEGAARD ${ }^{1}$ \\ «Tus ojos son demasiado puros para mirar el mal» (Hab 1, 13)
}

\author{
ÁNGEL VIÑAS VERA \\ Universidad Loyola Andalucía
}

\begin{abstract}
RESUMEN: El presente artículo quiere acercarse al misterio del mal en la obra de S. Kierkegaard. Tomando como punto de partida la obra lanzada al mundo en vida del autor, tanto la pseudónima como la firmada por él mismo, este texto aborda el misterio del mal y su relación con el Amor de Dios, misterio central del citado pensador. Aquí se pone en valor la importancia de acercarse al misterio de la iniquidad también desde los discursos edificantes así como en Las obras del amor. Al hacer esto aportamos una aproximación diferente al misterio del mal en la recepción kierkegaardiana y se pone de relevancia el amor como la manera de abordar el mal sin hacernos cómplices del mismo. Esto se hace posible, entre otros elementos, porque Dios y el que ama, mutatis mutandis, no ven lo malo del mal.
\end{abstract}

PALABRAS CLAVE: Kierkegaard; mal; amor; Dios; niños.

\section{Kierkegaard on God and Evil \\ "Your eyes are too pure to look on evil" (Hab 1, 13)}

ABSTRACT: This article aims to approach the mystery of evil in the work of S. Kierkegaard. Taking as its starting point the work launched into the world during the author's lifetime, both the pseudonymous writings and the ones signed by him, this text deals with the mystery of evil and its relationship with God's Love, which is the central mystery of the aforementioned thinker. The importance of approaching the mystery of iniquity also from the edifying discourses as well as in The Works of Love is emphasized. In doing this we bring a different approach to the mystery of evil in the Kierkegaardian reception and love becomes relevant as the way to approach evil without becoming accomplices to it. This is made possible, among other elements, because God and the one who loves, mutatis mutandis, do not see the evil of evil. KEY WORDS: Kierkegaard; Evil; Love, God,, Children.

El presente artículo quiere poner en valor la idea de Dios en Kierkegaard desde dos claves. Por un lado, se quiere mostrar cómo piensa a Dios sin hacerlo desde el mundo, eso supone radicalmente y en segundo lugar, la relación de Dios con el mal. Kierkegaard pensó el misterio de Dios sin tomar el mundo como modelo desde el que pensarlo. Su aproximación a este misterio viene marcada fundamentalmente por la idea del Amor absoluto. Esta idea central muestra una manera singular de entender la realidad divina en relación al mundo y al misterio insondable del mal. El Amor absoluto, como la dimensión esencial de Dios en Kierkegaard, es la clave para pensar el mal, sin enredarse en proyecciones antropológicas o en cosificar al objeto Dios. Su acercamiento no se hace desde la teología natural o desde una antropología filosófica que pusiera en valor alguna dimensión constitutiva del ser humano que remitiera directa o indirectamente al misterio divino.

1 Esta investigación se enmarca en el Proyecto $\mathrm{I}+\mathrm{D}+\mathrm{i}$ «Ética y justicia cosmopolita en la Escuela ibérica de la paz y la escolástica iberoamericana: aportaciones del pensamiento y tradición jesuita» (PEMOSJ2), ref. PID2020-112904RB-I00, Agencia Estatal de Investigación, Prof. Dr. Juan Antonio Senent de Frutos (IP1) y el Prof. Eduardo Ibáñez Ruiz del Portal (IP2). 
Fue Levinas quien afirmó que Kierkegaard había sido el primer pensador que había analizado la idea de Dios sin hacerlo desde el mundo². Intentaré acercarme, en primer lugar, a la idea de Dios como Amor absoluto como aparece en el pensador danés. Evidentemente es un tema demasiado amplio para poder ser abordado en toda su extensión en este artículo. Además tendré como marco de referencia no sólo los pseudónimos, sino toda la obra publicada en vida por el autor. Tanto la obra pseudónima como los discursos son material filosófico de primer orden. Casi todos ellos son leídos aquí como comunicación indirecta, como ha quedado de manifiesto en la tesis de la doctora Nekane Legarreta ${ }^{3}$. La categorización de los discursos edificantes como comunicación directa no nos parece la más adecuada, si seguimos las indicaciones que el mismo Kierkegaard hace en su obra.

En un segundo lugar, me acercaré al misterio del mal en la obra del pensador danés. De nuevo debo acotar el análisis a algunos textos que considero fundamentales para abordarlo. Los dos temas que aquí se van a tratar están íntimamente entrelazados. La distinción en dos apartados obedece a razones de método. En el desarrollo del mismo se verá la relación estrecha que guardan. $\mathrm{Al}$ analizar este tema en la obra de Kierkegaard, también quiero poner algo de manifiesto: la riqueza que supone considerar juntas la obra pseudónima y los discursos a la hora de estudiar los temas kierkegaardianos. El amor y el mal han sido abordados, a veces, acudiendo sólo a un tipo de producción, como si para hablar del amor de Dios hubiera que referirnos exclusivamente a los discursos, y por el contrario, para abordar el tema del mal hubiera que acudir a la obra pseudónima. Creemos que es mucho más rico el análisis de la filosofía kierkegaardiana abordándola desde su producción escrita a dos manos ${ }^{4}$.

Si quisiéramos expresar la idea fundamental de este artículo sirviéndonos de una cita bíblica de referencia, podría ser la siguiente: «Tus ojos son demasiado puros para mirar el mal», (Hab 1, 13). Kierkegaard puede que sea, entre todos los títulos que le han dado como pensador religioso, filósofo, esteticista, poeta, etc., un comentador de la Biblia, alguien que no deja de analizar y comprender el libro de nuestros mayores ${ }^{5}$. Esta cita del profeta Habacuc podría servirnos

2 «Es el primer filósofo que piensa a Dios sin pensarlo a partir del mundo», Levinas, E. De Dios que viene a la idea, Caparrós Editores, Madrid 1995, p. 182.

3 Legarreta, N. Método y objeto en la autoría de Kierkegaard o el arte de pescar con señuelos de pluma, Universidad Pontifica Comillas, Madrid 2013.

4 «Con la mano izquierda, yo ofrecí O lo uno o lo otro al mundo, con la derecha Dos Discursos edificantes, pero todos tomaron, o casi todos, con su derecha lo de la mano izquierda». SKS 16, 21. Synspunktet for min Forfatter-Virksomhed. El punto de vista sobre mi obra como autor. A partir de ahora seguiré citando siempre así, con los textos traducidos personalmente teniendo en cuenta las traducciones españolas, y con el título en danés y castellano. Los textos se citarán siguiendo la forma convencional SKS, seguido del capítulo y página.

5 «Una autoría que comenzó con $O$ lo uno o lo otro y avanzó paso a paso quiere encontrar aquí su decisivo lugar de descanso, al pie del altar, donde el autor, personalmente muy consciente de su propia imperfección y culpa, ciertamente no se refiere a sí mismo como un testigo de la verdad sino simplemente como una especie peculiar de poeta y pensador, 
de guía para acercarnos a tan magna empresa. En ella se nos anticipa que los ojos de Dios son de tal naturaleza o dignidad o sencillez que no miran el mal, como si la pureza de su ser repeliera el mal, lo echara fuera. Podría ser esta la mejor manera de no darle al mal un lugar preeminente. Pero, por otro lado, esta idea puede ser excusa para que Dios se desentienda de tantas injusticias y sufrimientos, lo que lo convertiría en un insensible cómplice y justificador.

El mal es una de las grandes cuestiones de la filosofía y la teología. Ella se ha querido analizar, comprender y asumir desde diversas y opuestas escuelas de pensamiento. Como el uso de la palabra mal es múltiple, más aún desde la Teodicea de Leibniz, ajustaremos su sentido, aunque quede sujeto a otras matizaciones posteriores:

Y es que la misma palabra mal posee múltiples sentidos, que sólo son discernibles en una elemental fenomenología del dolor. En ella aparece en seguida aquel mal que hasta tal punto es terrible y malo que no sólo tuerce, sino que rompe el hilo del sentido, el hilo de la vida. El mal pésimo y más hondo o pesante es el sinsentido: un contrasentido de tal furia destructiva que arruina el sentido y que, por tanto, desespera. Mejor dicho: nos hace desesperar, si caemos en sus manos, respecto de un conjunto de expectativas tan amplio que, quizá durante mucho tiempo, creemos haber desesperado enteramente. ${ }^{6}$

Este texto puede servirnos para marcar, antes de otras consideraciones que seguirán en el artículo, la primera aproximación al misterio del mal. En la tesis del profesor García-Baró el mayor de los males, la desesperación más aguda, no proviene del mal que sufrimos, sino del que hacemos. De ahí que su acercamiento al misterio del mal no sea tanto la especulativa o histórica sobre el origen del mal, sino el análisis de la acción. Algunos autores, cuando han querido acercarse al misterio del mal en Kierkegaard, han tomado como base el análisis del pecado y la angustia. Es un camino posible, transitado y trabajado en la bibliografía sobre el pensador danés. En él podemos acercarnos a la centralidad de la idea de pecado, y de la fe, en el acercamiento al misterio del mal. Baste recordar a estos efectos el texto de Ricouer Kierkegaard y el mal ${ }^{7}$. Ahí podemos encontrar el análisis de los dos libros que tratan más sistemáticamente las dos

el cual, sin autoridad, no ha tenido nada nuevo que mostrar sino que "ha querido una vez más interpretar, si cabe de una manera más íntima, el texto original de las relaciones de la existencia humana, el viejo texto, conocido, que nos entregaron a través de nuestros padres nuevamente." - (véase mi post scriptum al Post Scriptum Definitivo)». SKS 12, 281, To Taler ved Altergangen om Fredagen. Dos discursos para la comunión en viernes.

6 García-Baró, M. Del dolor, la verdad y el bien, Ediciones Sígueme, Salamanca 2006, p. 41. En especial el capítulo El dolor, pp. 41-65.

7 Ricouer, P. «Kierkegaard et le mal», Revue de théologie et de philosophie, 13 (1963) que se encuentra en línea en https://www.e-periodica.ch/cntmng?pid=rtp-003:2006:56::492 el 16 de enero de 2019. Esta línea de investigación ha sido desarrollada también en WAHL, J. Kierkegaard. L'un devant l'Autre, Hachette Littératures, Paris 1998; LARRAÑETA, R. La interioridad apasionada. Verdad y amor en Søren Kierkegaard, Editrorial San Esteban, Salamanca 1990; SuAnces, M. Sören Kierkegaard. Tomo II: Trayectoria de su pensamiento filosófico, UNED, Madrid 1998; GoÑI, C. El filósofo impertinente. Kierkegaard contra el orden establecido, Editorial Trotta, Madrid 2013. 
categorías y poner en el centro del debate filosófico en torno al mal las categorías de la desesperación, la angustia y la fe. Ese camino es más conocido, como ya he indicado, pero considero que necesita ser enriquecido con los planteamientos que aquí se van a hacer. El camino que sugiero no es fundamentalmente la pregunta por el origen del mal, por la implicación personal en el origen histórico o metafísico del mal. La cuestión capital aquí no es tanto la clásica de la teodicea sobre el origen y naturaleza del mal. La perspectiva que aquí se añade es la que proviene de los análisis kierkegaardianos que, podríamos decir, son más de tono fenomenológico. Recuperar para estos temas los discursos edificantes es esencial. Voy a mostrar algunos elementos que Kierkegaard enfatiza sobre el misterio del mal sin los cuales el voluntarismo y la culpabilidad serían lo central de su pensamiento, e incluso, olvidaríamos la repercusión que tiene el mal en la propia divinidad. La cuestión no es sólo, aunque es capital, la implicación del ser humano en el origen del mal, sino qué misterio es el mal que le afecta a Dios. Por otro lado, sus análisis nos llevarán a ver cómo es la mirada del niño y del amante, del que ama siempre y en todo lugar, al misterio del mal. Con ello no se resuelve la pregunta del origen del mal, pero las indicaciones que aquí se expondrán impiden reducir el planteamiento kierkegaardiano al origen angustioso del pecado, la desesperación del ser humano y la consiguiente salvación por la fe. En este texto se dirá que el camino del amor puede iluminar el misterio del mal de una manera que, aun no estando en oposición al anteriormente indicado, amplía la perspectiva y el misterio que estudiamos. Los análisis que abren esta perspectiva no son aquí abordados en su totalidad, pero espero que puedan motivar posteriores análisis más amplios de los temas aquí anunciados.

Es cierto que para el tema del mal sería necesario un esbozo o análisis del lenguaje, de los significados de la palabra mal, malo, maldad, sufrimiento, etc. Un análisis fino del lenguaje sobre el tema, nos ayudaría y desbrozaría algunas preguntas, suprimiría algunas y haría resurgir otras. En la obra de Dalferth ${ }^{8}$ podemos descubrir estos análisis, a veces exhaustivos. Si no nos detenemos aquí, además de la razón obvia de acotar el ámbito de reflexión, es por dos razones fundamentales. La primera es el respeto al acercamiento de Kierkegaard a la cuestión. El pensador danés no es fácilmente encasillable o sistematizable, al menos de una manera única. Su obsesión no es con las palabras, y eso que el variado uso de diversos registros del lenguaje es exquisito. Para él, lo esencial ocurre antes y después de las palabras. Es lo que se realiza en la acción, en el apropiarse, en las verdades que se hacen verdad en cada uno, en la pasión, en la interioridad, en la corporalidad de nuestras acciones, en la vivencia del tiempo. Kierkegaard no quiere afinar la expresión o sintetizar una idea, sino que quiere llegar a su querido lector para que pueda encontrar motivos para vivir y sufrir, para que pueda encontrar alegría perfecta.

8 En especial véase el libro Dalferth, I., El mal. Un ensayo sobre el modo de pensar lo inconcebible, Ediciones Sígueme, Salamanca 2018. Es un buen ejemplo de análisis de los términos que usamos para dirigirnos al mal, de las dimensiones del mismo así como intentar definir y ajustar lo usos de la semántica del mal. 
La segunda razón es que el tema en cuestión no puede quedar reducido a un debate terminológico. Al final de las distinciones y aclaraciones habrá una realidad, la del mal, que lo más grave no ocurre en las palabras. Es cierto que el lenguaje es creador de realidad o simplificador de la misma, o generador de males. Pero lo malo del mal no es su manera de decirlo, sino su manera de sufrirlo, el sinsentido que introduce en el ser humano. El mal muchas veces es lo indecible. Esto no es una apología del silencio ante el mismo. Posiblemente es de lo que hay que hablar en cada momento, pero puede que la cuestión decisiva que introduce lo malo del mal no quede comprendida jamás ${ }^{9}$.

\section{Dios como Amor absoluto}

Kierkegaard repite varias veces una misma idea: Dios es el que puede enseñar a cada individuo cómo ha de amar, porque Dios es Amor (1Jn 4, 8). El Amor que es Dios es la piedra angular sobre la que se basa la comprensión del misterio último de Dios en su filosofía. Para el autor danés, Dios es Amor y no fundamentalmente Poder o Libertad o Naturaleza o Ser ${ }^{10}$. Es la bóveda donde se enmarca toda su autoría, una idea que se repite a tiempo y a destiempo. El Amor es la eternidad y la eternidad es Amor absoluto. Un Amor que nunca hemos vivido nosotros, los seres humanos en toda su plenitud por la diferencia insalvable entre cualquier criatura y Dios. Esta diferencia no remite fundamentalmente, en Kierkegaard, a una diferencia ontológica, esencial o de naturaleza. Es una diferencia radical de bondad, de lo que está más allá del ser, del bien.

Aunque el acercamiento al misterio de Dios en Kierkegaard recorre muchos y variados recovecos, su querido Sócrates aquí tampoco es olvidado, y está vinculado especialmente al aparecer de Dios en el Cristo ${ }^{11}$. Para entender algo del Misterio de este Amor absoluto del que nos habla el cristianismo hay que

9 «Auschwitz, en cambio, abarca todo lo que queremos decir cuando hoy en día usamos la palabra mal: una maldad absoluta que no deja espacio para ninguna forma de aprecio ni de expiación». Neiman, S. El mal en el pensamiento moderno. Una historia no convencional de la filosofía, Fondo de Cultura Económica, México 2012, p. 28. Este magnífico libro debe quedar consignado por la profundidad con la que aborda el tema del mal. Sus análisis no disuelven ni justifican, sino que ayudan a hacernos cargo con mayor rigurosidad del misterio del mal.

10 «Por él mismo, ¿el deseo humano puede aspirar a Dios? Si esta aspiración existe, ¿ella tiene el título de llamarse "amor"? ¿Y que alcanza justamente por las palabras "Dios" y “amor" en estas preguntas?, Chalier, C. La gravité de l'amour. Philosophie et spiritualité juives, Presses Universitaires de France, Paris 2016, p. 17. (Traducción personal)

11 La lectura que se hace aquí del sabio de la antigüedad, como también llama Kierkegaard a Sócrates, no subraya la discontinuidad o salto entre los dos. La omnipresencia de Sócrates en toda su obra entregada al mundo pone de manifiesto, además de otras muchas razones que han sido abordadas en otros trabajos de investigación, que nunca es abandonado o dejado de lado como un escalón superado. Con Sócrates, no de él, podemos aprender mucho del Amor y el misterio del mal. Remito al trabajo S. Kierkegaard: Una teoría del cielo, en https://dialnet.unirioja.es/servlet/tesis?codigo=110157, con consulta en la web de 21 de enero de 2019. 
mirar detenidamente cómo ha venido Dios en el Cristo. La manera de venir, el cómo, nos permite intuir el qué de su amor. No se trata de ver las obras del amor de Dios porque nunca las obras ni de él ni de nosotros encierran el amor en su pureza. El Amor es una fuente invisible, de ahí que Kierkegaard hable más de las obras del amor ${ }^{12}$. Nuestras acciones humanas pueden encubrir o dificultar la mirada de aquel que quiere contemplar el amor. Ya Kant nos hizo ver que el mejor camino para describir una acción buena era intentar mostrar en qué consistía una voluntad santa. De manera parecida, mutatis mutandis, Kierkegaard nos muestra cuáles son algunas obras del amor, porque siempre el amor queda algo desconocido y oculto a nosotros.

Si queremos acercarnos al Amor absoluto que es Dios nos debemos acercar, según lo dicho anteriormente, a lo que se conoce como el dogma de la encarnación. ¿Cómo viene Dios en el Cristo? Cuando Dios viene al mundo, ¿cómo lo hace? ¿Qué forma toma? Como incógnito, nos indica Kierkegaard. ¿Qué supone esto para Dios y el mundo? ¿Qué nos dice esta manera del ser de Dios? En el Cristo, Dios aparece como un hombre normal y común a tantos hombres. Y ahí está Dios. Ese es el escándalo que se le presenta al ser humano. La manera de vivir, su estar incógnito, que imposibilita toda comunicación directa, es fruto de su amor para con el ser humano:

Así tampoco domina en ningún momento, como desde fuera, el sufrimiento, sino que está realmente implicado en el sufrimiento, y prueba el cáliz de lo puramente humano, que consiste en que la realidad sea más espantosa que la posibilidad, de suerte que Él, que escogió la incognoscibilidad, sin embargo, sufre realmente como si estuviese cogido o se hubiese cogido a sí mismo en la incognoscibilidad. Esta es una especie extraña de dialéctica: que Él, el omnipotente, se ate a sí mismo; y hace esto tan omnipotentemente que se siente realmente atado, sufre bajo las consecuencias de su amorosa y libre decisión de hacerse un hombre singular. ${ }^{13}$

12 Cf. SKS, 9, 13, Kjerlighedens Gjerninger."Kjerlighedens skjulte Liv og dets Kjendelighed paa Frugterne», «La vida escondida del Amor y su recognoscibilidad en los frutos». Este capítulo, que es el primero de este libro, comienza intentado avisar sobre dos posibles lecturas del amor en relación a las obras. Por un lado, la capacidad de ver directamente al amor en las obras, como si las obras vistas externamente pudieran manifestar directamente el amor. Por otro lado, quiere subrayar que un amor que no conlleve obras sería difícil de reconocer como tal por nosotros. Ni una relación directa de las obras al amor que las expresa, ni una imposibilidad de manifestarse el amor en las mismas. De ahí que sólo el Amor sea capaz de decir últimamente si una obra es de amor o no, aunque eso no es óbice para que podamos hablar de las obras del amor. Aquí, como en otros temas, el cómo se actúa es más decisivo aún que el qué se hace. En este libro no encontramos discursos sobre el Amor que es Dios, sino meditaciones cristianas sobre las obras del amor. ¿Quién sería el juez de dictaminar si una obra que vemos nace del Amor invisible, como el amor desea y quiere? Aunque pueda parecer algo obvio decirlo, debería ser el mismo Amor. Este libro no se sitúa, como hace Kierkegaard con muchos temas aunque lo sigan catalogando de ultra luterano algunas lecturas, en el problema clásico de la fe y las obras, sino mucho antes, donde la dogmática podría echar un ojo antes de lanzarse a analizar aquellos otros temas tan decisivos.

13 SKS 12, 136, Indøvelse i Christendom. Ejercitación del cristianismo. 
El anonimato en su venida es una decisión libre del Hombre-Dios. Al hacerlo así, entra en el espesor del sufrimiento humano y asume el vivir como uno de tantos, pasando desapercibido. El misterio del amor de Dios que se revela especialmente en el Cristo queda vinculado a su vida y destino. El mal no está en el origen de este movimiento encarnatorio, al menos como idea central.

¿Cómo se manifiesta el amor de Dios al venir al ser humano en el Cristo? ¿Por qué llamarlo amor y no venida todopoderosa humillante? Dios mismo se auto-limita, se ata a sí mismo por amor a nosotros, y decide hacerse hombre sufriente como nosotros. Y sufre por amor las consecuencias de esta decisión. Este misterio puede ser leído como una radicalización de la palabra dada por el Señor a Moisés sobre la imposibilidad de ver a Dios cara a cara y seguir vivo. Querer mediante algún razonamiento o experiencia o sentimiento estar cara a cara y directamente con el misterio santo nos pone en el camino de la idolatría más que en el del verdadero sentimiento religioso. La idea de Dios como ser o naturaleza que está presente en nosotros sin que nosotros seamos conscientes de nada, no es que no aparezca, es que no es relevante para el pensador danés. Su venida nos remueve aunque lo que pida de nosotros sea una vida aparentemente normal, habitada por una pasión feliz.

¿Y qué le ocurre a este amor cuando viene a este mundo? ¿Qué consecuencias tiene que venga sin el poder de la fuerza, de la naturaleza o de la cultura? Este Amor sufre ${ }^{14}$. Sufre porque ama, porque ha decidido amar, si es que es posible hablar así de Dios, como nos ponía sobre aviso C. Chalier al principio de este punto. Kierkegaard, que tanto ha hablado y escrito sobre la culpabilidad y la pecaminosidad del hombre, nos habla del sufrimiento insondable del Santo, de Dios. No se atreve a ir mucho más allá pero nos lo anuncia: «iQué consuelo sufrir como culpable por necesidad, pero qué será sufrir como inocente! ${ }^{15}$ Este sufrimiento se debe, entre otras cosas, a que sabe que su Amor está ante una encrucijada difícil, la de Aquel que quiso crearnos espíritus libres y que no quiere atraernos a sí sin el concurso de nuestra libertad. No se trata de méritos, de fe o de obras. Es algo anterior o de otro orden. Se trata de que si el hombre no va a Él con pasión absoluta y el corazón indiviso, ni llegará a Dios ni será bienaventurado ${ }^{16}$.

14 «Dios en su amor sufre más que tú» WAHL, J. Études Kierkegaardiennes, Éditions Fernand Aubier, Paris 1938, p. 374.

15 SKS 4, 240, Philosophiske Smuler. Migajas filosóficas.

16 «Así la alegría del Dios consiste en vestir a los lirios con mayor magnificencia que a Salomón. Pero si pudiéramos hablar de comprensión, el lirio se encontraría en una penosa ilusión si, al contemplar sus nobles ropajes, pensara que las vestiduras son el motivo de ser amado. Ahora está contento en el prado jugueteando con el viento, tan despreocupado como su soplo. En cambio, conocer todo aquello lo ajaría y no tendría candor para levantar la cabeza. Esa sería la pena de Dios, pues el brote del lirio es tierno y pronto se troncha. Pero si el instante tiene importancia decisiva, ¡qué inefable se vuelve su pena! Había un pueblo que entendía mucho de lo divino. Este pueblo pensaba que ver a Dios era morir. - ¡Quién entiende esta contradicción del dolor: no revelarse es la muerte del amante, revelarse es la muerte del amado!»SKS 4, 236, Philosophiske Smuler. Migajas filosóficas. 
El Amor no fue amado. Y eso pasa y puede seguir pasando. Pero no por eso, según la tradición cristiana acogida por Kierkegaard, deja de amar. Su sufrir es incomprensible para un culpable. De alguna manera, mi experiencia del sufrimiento y el mal, en primera persona prefiero enunciarlo, no la vivo como el sufrimiento del totalmente inocente. En mí no cabe nombrar el sufrimiento como si yo fuera el santo, aunque eso no quiere decir que lo que sufro es consecuencia de mi no-inocencia. Ante el misterio del mal, Kierkegaard no hace silencio ante el misterio del Amor de Dios, pero tampoco nos hace un discurso al margen del existente. Tampoco quiere hacer un tratado sobre un Amor que se refiera más a la naturaleza que a la libertad. El Amor absoluto que es Dios no remite a algo más profundo que fuera naturaleza, ser, poder, voluntad. Parece que el Amor absoluto es lo último, lo definitivo. Y que este amor, hablando humanamente, se relaciona más con la libertad, con el querer, incluso con cierta ansia ${ }^{17}$. Porque parece que Dios desea ansiosamente que el ser humano le quiera como le vendría bien al ser humano que quisiera a Dios, es decir, que lo hiciera libremente. De lo contrario no se desata el nudo del pecado primero, ni entra el existente en una nueva vida. De lo contrario, y siempre con cautela, Dios no podría darle la alegría eterna porque el ser humano no podría recibirla.

¿Qué resonancia tiene la venida de este Amor al individuo? El amor que es Dios es vivido por el individuo, fundamentalmente, desde su experiencia de pecado ${ }^{18}$. Nos acerca más al amor de Dios la experiencia del fallo, del pecado y de la culpa que la experiencia triunfante o gloriosa de los supuestos bienes. Dudar de uno mismo puede ser una puerta maravillosa para entrar en el misterio del Amor que es Dios: «Cuando, en efecto, por sus miles cuestiones la duda quiere perturbar a la fe y da la apariencia de que Dios no contesta, la conciencia de culpa enseña entonces al creyente que es él quien no puede dar una sola respuesta a estas miles de cuestiones: ergo, Dios es Amor» ${ }^{19}$. La conciencia de la culpa es el mejor socorro siempre que no la pongamos a nuestro servicio. No hay mejor camino para descubrir algo del Amor insondable que es Dios que la experiencia de la culpa. Aunque evidentemente la mejor manera de acercarse al amor santo sería la inocencia, que igual no es ni muy consciente del misterio que descubre en su vida. De ahí que no hagamos una apología ni de la culpa ni de la experiencia del pecado como esenciales para conocer el Amor de Dios. La insistencia de Kierkegaard en el pecado o la culpa es

17 El análisis del ansia, y no sólo de la angustia, en Kierkegaard nos ayuda a poder descubrir que aquella puede estar presente en Dios y, de alguna manera, en la naturaleza. La identificación ansia-angustia puede que pierda matices importantes en los análisis que acometemos. Cf. LegarReta, N., op. cit., pp. 211-235.

18 «El primero de estos rasgos es que ningún dolor supremo tiene por objeto a quien lo sufre. El mayor de los males que a mí solo me afecta no causa, de ninguna manera, un dolor supremo, porque no es un verdadero ejemplo del mal a secas. Por mucho que quiera yo fingir que no hay derecho ni en el cielo ni en la tierra a este dolor mío, sé siempre que no soy inocente. Sé que soy, oscuramente, el portador de una responsabilidad infinita, respecto de la cual me encuentro, desde luego, culpable». García-BARó, M., op. cit., p. 45.

19 SKS 8, 370, Opbyggelige Taler i forskjellig Aand. Discursos edificantes en diferentes espíritus. 
para poner en valor el Amor de Dios, no la maldad del ser humano. Pero si el Amor de Dios fuera visto desde el prisma del pecado o la culpa, ¿no estaríamos de nuevo haciendo una proyección a la divinidad de nuestra realidad?

Y si ahora el singular alegre pensamiento de que Dios es amor, es el que llena tanto el cielo como la tierra; es «la alegría y, yo lo digo otra vez, de alegría» la singular fuente; entonces esto es también alegre, que está absolutamente firme, porque ninguna, ninguna duda puede sacudirla y no lo puede tampoco llevar a ello. Porque la conciencia de culpa es el poderoso que guarda este tesoro; en el instante mismo en que la duda quiere tocarle, está perdida, el poderoso la precipita en el abismo, en la nada de donde ha venido; y en el instante mismo la fe recuerda así su objeto, que Dios es amor. ${ }^{20}$

Kierkegaard no quiere llevar al individuo a sentirse culpable y dejarlo ahí a su suerte. Él ha intuido que con esa puerta el hombre puede acceder al bien más preciado, al inimaginable: que Dios le ame a él. Pero siendo este el bien más preciado para la persona, el Amor que es Dios es un bien en sí más perfecto aún. Es bueno que me amen, por decirlo en primera persona, pero es realmente perfecto que Dios sea Amor. Tanto si me ama a mí como si no. Dios es amor no es equivalente al gozo por recibir el amor de Dios. Al igual que el cielo no recibe su perfección de que sea mi cielo, o que la humanidad pueda participar del mismo, sino de que el Bien perfecto, el Amor misericordioso, el cielo, la alegría perfecta existan. La alegría del bien no es la que recibo del bien, sino la alegría de que el Bien triunfe, de que el Amor absoluto lo sea y no deje nunca de serlo.

No sólo se trata de descubrir o saber que Dios ama a la humanidad, sino que Dios le ama a cada individuo en concreto. Al igual que el pecado es de cada uno, lo que realmente individualiza al ser humano en este planteamiento es que el Amor le ama. El pecado y la conciencia de culpa es puerta, no es llegada para el que se ha encontrado con Dios en el Cristo. Además no tiene por qué ser la única puerta posible para acceder a este Amor. El Amor de Dios es el Bien supremo para Kierkegaard. Nada es igualable a ello. El pecado y la conciencia de culpa no están al mismo nivel. Lo que hace que el individuo sea individuo es que es Amado por el Amor que no fue amado.

Damos ahora un paso más, adentrémonos en una idea que Kierkegaard desarrolla en varios momentos. Ella nos abrirá cada vez más a la vinculación entre el amor de Dios y el misterio del mal. ¿Qué hace Dios con el pecador? ¿Cómo lo ama? Cubriendo sus pecados en el Cristo:

Él oculta totalmente (la multitud de pecados), hasta la última coma. Cuando un hombre se coloca ante otro, y con su cuerpo lo cubre del todo, entonces nadie, nadie puede ver lo que él esconde; de la misma manera, Jesucristo oculta con su cuerpo santo tu pecado. ${ }^{21}$

20 SKS 8, 370-371, Opbyggelige Taler i forskjellig Aand. Discursos edificantes en diferentes espíritus.

${ }^{21}$ SKS, 12, 299, To Taler ved Altergangen om Fredagen. Dos discursos para la comunión en viernes. 
Un hombre puede cubrir con su amor los pecados de su prójimo. Un ser humano bueno debe hacerlo. Debe hacer como que no los ve. Puede, con su amor, cubrirlos y no ponerlos a la luz. Al hacerlo, el amante cubre sus muchos pecados. Es un doble movimiento. El que cubre los pecados del otro con su amor, cubre los suyos. Sin embargo, los ha visto y de alguna manera, se sabe culpable como el otro, o más. Pero el Cristo no cubre los pecados igual. Su Amor santo le lleva a cubrir/ocultar (at skjule) los pecados sin necesidad de cubrir los suyos. Él no cubre los pecados de los demás cubriendo los suyos. Y, en segundo lugar, él no ve los pecados, sino que los entierra, los tapa. ¿Cómo? Con su cuerpo santo. Se pone Cristo delante del pecado para que no sólo en el día del juicio se salve, sino para que el hombre se viva a sí mismo como cubierto por su Amor. Cristo no quiere que el ser humano esté mirando continuamente su pecado, sino que cayendo en la cuenta de su fragilidad, mire al Amor que viene a él de forma inmerecida. La mejor manera de no estar obsesionado con el pecado es mirar al otro, y en este caso, al Cristo. La puerta de la dicha se abre desde fuera ${ }^{22}$, pero no sin el concurso de quien está dentro, sumergido en la culpa que su libertad ha podido producir. Esto nos pone en la antesala de poder analizar, en el siguiente apartado, el misterio del mal.

\section{El Misterio DEL MAL}

¿Cómo vivir la experiencia del mal ante el Bien supremo? ¿Qué es lo malo del mal? ¿Puede ser entendido sin hacerse uno malo, de alguna manera? ¿Qué dice el Amor absoluto ante la experiencia del sufrimiento? ¿Se puede mantener, a la vez, que Dios es el Amor absoluto ante la experiencia aguda del sufrimiento?

El ser humano que se conoce a sí mismo y se vive en relación al bien perfecto no se vive fundamentalmente desde la distinción entre las cosas buenas y malas, la dicha o la desdicha, etc. Hacerlo sería ya haber caído en las redes del mal, de alguna forma.

Pero cuando en el corazón habita el amor, entonces el ojo tiene el poder de cultivar con su amor lo bueno en lo que es impuro; pero es que este ojo no ve lo que es impuro sino lo que es puro, que ama y cultiva con su amor al amarlo. Sí, hay un poder de este mundo que, en su lenguaje, traduce el bien en mal, pero hay también un poder de arriba que traduce el mal en bien, y es el amor que cubre la multitud de los pecados. ${ }^{23}$

El mundo es capaz de convertir un acto bueno, una persona buena, en algo malo. Es demasiado frecuente ver cómo el actuar bondadoso de alguien da

22 «iAy! La puerta de la dicha no se abre hacia dentro, de tal manera que uno pudiera abrirla de un empujón lanzándose sobre ella, sino hacia fuera; por eso no hay nada que hacer». SKS 2, 32, Enten/Eller. Første del. O lo uno o lo otro. Primera parte.

${ }_{23}$ SKS 5, 71 Tre opbyggelige Taler (1843). Discursos edificantes. Tres discursos para ocasiones supuestas. 
pie al peor de los males. El mundo tiene ese poder. ¿Por qué tiene ese poder el mundo? Porque se lo hemos dado, de alguna manera. Al mundo le hemos dado el poder de juzgar, de valorar, de nombrar las realidades. En el mundo pasa de todo, incluso que el bueno sea considerado un ser despreciable que hay que quitar de en medio. Pero el amor, y este es el segundo punto que queremos anotar de este texto, también tiene un gran poder: la capacidad de traducir el mal en bien. Los hechos acaecidos pueden que sean los mismos que son valorados en el mundo de forma diversa. El amor, sin embargo, los traduce y los vive de otra forma. El amor es más fuerte que el mal no porque lo haga desaparecer, sino porque le quitar el poder. El mal querría devorarnos sin que nos diéramos cuenta. El amor es la respuesta de un individuo que ante el asombro del mal, ama. Éste no quiere enredarse en las razones ni en las consecuencias nefastas del mal. Pero no por ello deja de amar a todos.

$\mathrm{El}$ amante, es decir, el que ama, hace esta traducción en primera persona del singular. No se trata de interpretar que el mal que sufre otro es un bien para él. No se trata de hacer una teodicea para el otro como si yo pudiera estar en el lugar del Absoluto. Kierkegaard no hace eso. Lo que hace es poner de manifiesto lo que Job hizo, lo que también hizo Abraham. Es lo que puede hacer un ser humano. Kierkegaard nos dice que esta vivencia es edificante para el hombre. El alcance y sentido de su texto es ese.

El que ama vence al poder del mal, al poder del mundo amando. $\mathrm{Y}$ al hacerlo consigue dos cosas: la primera es vencer el poder del mal a base de bien. Nótese que, como ya he indicado, el individuo sabe que no puede vencer el mal. Pero sí puede quitarle su aguijón mortal, su desesperación o el hacernos malos. Pero, en segundo lugar, debe hacer el trabajo más difícil: remitir a Dios la victoria ${ }^{24}$. Si el individuo considerara que él vence al mal por su propia cosecha y fuerza, hincharía su ego y el mal no sería eliminado de raíz. El coraje de ganar la primera batalla, es decir, hacer frente al poder del mal con el amor, es inmenso. El coraje de la segunda es mayor aún. Ganar es de fuertes. Reconocer quién ha ganado es de mayor valía. Así, el amante abre la posibilidad de ganar incluso al vencido, consigue que el enemigo o el malo que le está haciendo daño sea amado y ganado, junto con él, para el Bien. El que ama quiere que triunfe el Amor, no que triunfe él. El bueno no quiere ganar a toda costa. Quiere que a toda costa gane el Bien sobre todos. Y el Bien no gana si no nos vamos haciendo buenos.

El que ama, además, no ve el mal, ni lo descubre.

La interioridad decide, entonces, lo que un hombre descubre, y lo que encubre.[...] Cuando en el corazón habita el amor, entonces el ojo está cerrado y no descubre la obra manifiesta del pecado, y menos aún la encubierta, pues «el que guiña el ojo tiene en cuenta el mal» (Prov 10,10), pero el que

24 SKS 9, 329, Kjerlighedens Gjerninger. Las obras del amor. "Luego un ser humano solamente se mantiene firme después de haber vencido, si justo en el instante de la victoria le cede la victoria a Dios». Las obras del amor. 
comprende el guiño del ojo, ése no es puro. Cuando en el corazón habita el amor, entonces el oído está cerrado y no oye las palabras del mundo ni la amargura de la blasfemia, pues el que dice «raca» a su hermano, él es culpable ante el consejo, pero el que lo oye cuando se lo dicen, ése no es perfecto en el amor. ${ }^{25}$

El que ama se sitúa ante el mal como si este no fuera, no estuviera. Aquél ama al otro y cierra su corazón al mal que está delante. Amar es, entre otras cosas, esto. Es extraño esto que nos indica Kierkegaard porque es difícil entender cómo podría llamarlo mal, si no lo ve realmente. ¿Significa que es indiferente al mal? ¿Quiere decirnos que es realmente ciego y por lo tanto vive en un mundo ideal donde el mal no aniquila a los hombres? Analicemos también esta cita de una obra posterior:

El amante no descubre nada, y en consecuencia cubre la muchedumbre de los pecados, que puede ser encontrada mediante descubrimiento. [...] Y el amante no es ni quiere ser un entendido en el mal, sino que a este respecto es y permanece siendo, quiere ser y permanecer siendo un niño. [...] Entonces, ¿qué es lo que le falta al niño, qué es lo que con tanta frecuencia convierte la narración de un niño en una mofa profundísima respecto de los mayores? Es entender el mal, y que el niño carece de conocimiento del mal, y que el niño ni siquiera tiene ganas de entenderse con el mal. En este aspecto, el amante se asemeja al niño. Porque en el fondo, a todo entender acerca de algo le sirve de base el que haya un entendimiento entre el que ha de entender y lo que ha de ser entendido. Por esta razón, entender acerca del mal (por más que él mismo quiera imaginarse o quiera hacer creer a otros que puede conservarse completamente puro, que se trata de un entender puro acerca del mal) significa, sin embargo, entenderse con el mal; y si no hubiera este entendimiento, el inteligente no tendría ganas de entenderlo, detestaría entenderlo, y entonces tampoco lo entendería. ${ }^{26}$

El amante hace algo parecido a lo que hace el niño cuando juega: «Lo infantil aquí está en que el amante, como en un juego, no ve con los ojos abiertos lo que está teniendo lugar justo delante de él; lo solemne está en que es el mal lo que él es incapaz de ver ${ }^{27}$. Trayendo la experiencia del niño que viviera entre personas malas, Kierkegaard nos ayuda a pensar lo impensable: la primera mirada del ser humano al mal. ¿Cómo sería entonces ese ver sin ver, ese mirar sin mirar? Es cierto que si de alguna manera uno comprende el mal que está haciendo otra persona, no puede ser uno del todo inocente. Como se nos dice en el texto anterior sobre el texto de Proverbios, el ser humano que es capaz de ver el mal que está ocurriendo, sus manifestaciones, sus intencionalidades, la posibilidad que está ahí realizándose, no puede ser ya del todo inocente. ¿Qué podemos ver en el niño?

25 SKS 5, 70, Tre opbyggelige Taler (1843). Discursos edificantes. Tres discursos para ocasiones supuestas.

26 SKS 9, 283-284, Kjerlighedens Gjerninger. Las obras del amor.

27 SKS 9, 285, Kjerlighedens Gjerninger. Las obras del amor. 
El niño no ve qué sea lo malo. De forma parecida al relato mítico de Adán y Eva, el niño no sabe en qué consiste lo malo del mal. Él sólo puede sufrir, sentir pena, llorar. No hace ningún razonamiento para concluir que lo que está viendo es malo. Él sufre ante lo que ve. De ahí que a veces sus respuestas a las personas que están ahí sufriendo nos parezcan tan ilusorias o tan poco realistas. El niño no sabe ver las causas libres y aterradoras que han producido lo que está contemplando. Por eso da consejos a la situación que nos parecen infantiles. Kierkegaard es muy precavido con el acercamiento al mal de quien, queriéndolo entender, al final llega a justificarlo. Y justificar el mal es, de alguna manera, hacerse malo con él. $\mathrm{O}$, al menos, colocarse en un lugar que ya no es el del existente singular.

Kierkegaard no hace aquí una defensa de la cultura o el contexto o la tradición o lo heredado para decir que el mal es lo que se dice que es el mal. De aquí se derivaría, caso de ser cierto, que el niño no supiera nada del mal. Lo que está intentando ver es cómo el ser humano se sitúa ante el mal. El que entiende el mal, de alguna manera, se entiende con él. El mal es lo que no puede ser entendido del todo sin dejarse atrapar en él. Este misterio de la iniquidad no queda reducido a las cosas malas que hacemos, ni es sólo el pecado que hace el ser humano, sino que el mal es esa realidad en la que no es posible habérselas con ella sin dejarse afectar. No se puede entender el mal sin hacerse malo. Como el mal está presente en el mundo de muchas maneras, se hace necesario el coraje de amar y creer para quitarle su malicia, el coraje para no verlo y no caer en las redes de querer entenderlo para salvarnos de su mal.

La mejor teodicea es amar, según lo que llevamos dicho. El mal debe ser batallado en otro campo, ni negándolo ni afirmándolo. Amarlo todo pacientemente parece que ayuda más a vivir ante el mal, porque parece que es el camino en el que no nos hacemos malos. El que ama al otro saca al otro de las garras del mal. Si no le amo, lo considero malo e indigno de ser amado. Es como si lo diera por perdido o si dijera con mis actos que el mal recibido es merecido. Si toda nuestra libertad, aún enmarañada, estuviera vertida y dirigida hacia el bien nos pasaría algo así: «Si — sit venia verbo- la libertad permanece en el bien, entonces no sabe nada en absoluto del mal ${ }^{28}$. Es curiosa esta afirmación de Kierkegaard ya que parece que el individuo no ve lo que realmente debe ser visto. De nuevo la misma idea en otra obra diferente, en esta obra pseudónima. Si el ser humano no combate contra el mal viendo sus artimañas, ¿cómo podrá vencerle? Pero Kierkegaard piensa que el mal es más astuto que muchos hombres y, a veces, con el buen motivo de querer luchar contra él, se le hace más grande. ¿Y Dios? ¿Cómo se sitúa ante el mal?

En este sentido se puede decir de Dios — no es mía la culpa si alguno lo interpreta al revés- que no conoce el mal. Con esto no quiero decir en modo

28 SKS 4, 413, Begrebet Angest. El concepto de angustia, (capítulo cuarto dedicado al pecado y la angustia). 
alguno que el mal sea meramente lo negativo, lo que hay que superar; pero el absoluto castigo del mal consiste en que Dios no sepa nada de él, ni quiera ni pueda saberlo. ${ }^{29}$

Es conocido el texto de Santo Tomas sobre el conocimiento de Dios del mal. Nos dice en la Suma Teológica que Dios no tiene idea del mal ${ }^{30}$. El contexto desde el que se hace en Tomás es bastante diferente al existencial del filósofo danés, pero ambos apuntan a que Dios no puede tener una relación con el mal como con otras realidades. Aquí Kierkegaard nos hace ver que Dios no puede dejarse enredar con el mal ni debe ser definido el misterio de aquel por su referencia a este. El mayor castigo que se le puede hacer al mal, por parte de Dios, es no mirarlo. El mal es de tal magnitud que ni Dios lo ve ni lo conoce. El mal no es una negación o privación de ser $^{31}$. Para salvar la Bondad absoluta de Dios y su Amor, Kierkegaard no hace a Dios cómplice de las estrategias del mal. El mal no es visto por Él. Si Dios viera el mal nos cabría la duda de si se complace en él, lo usa para otros fines o lo justifica de algún modo. Dios es el Anti-mal no sólo porque luche contra el mal, sino porque es el Amante que anima a amar más cada día. Dios es el Bien supremo sin mancha de mal. Dios, el Bien supremo, no quiere estar al servicio del mal. ¿Qué pasó cuando Dios se hizo hombre y vio el mal que estaba en el mundo? El mal no estuvo al principio ni parece que estará al final de historia. ¿Afectó el mal al Hijo de Dios? ¿Cómo? El hecho misterioso de la tentación del mismo Hijo de Dios nos pone en la pista de un mal que no puede quedar reducido a las diversas figuras de la finitud humanas: "A fin de cuentas, la befa y el escarnio propiamente no causan ningún daño, a no ser que el escarnecido se dañe descubriendo, es decir, amargándose; pues al amargarse, descubre la muchedumbre de los pecados $»^{32}$.

$\mathrm{Su}$ Amor santo guarda silencio en el momento en que va a ser juzgado. Su silencio es manifestación de su amor. El Cristo, al guardar silencio ante el mal que no ve, nos da tiempo, futuro. Nos cubre los pecados con su silencio, con su cuerpo santo. El Cristo no quiere que el mal sea subrayado ni puesto a la luz. Él no quiere que el mal avance. Por eso el peor mal para el Amor es que el mal sea descubierto, esté a la luz y todos puedan creer que el mal está en el otro. Parece

29 SKS 4, 413, Begrebet Angest. El concepto de angustia.

30 Para un acercamiento a estas ideas desde otra tradición filosófica, como la tradición tomista, podemos ir a Garrigues, J.-M., Dieu sans idée du mal. Méditations sur la miséricorde, Éditions Ad Solem, Paris 2016. Es la tercera edición del texto. En ella podemos descubrir un análisis de la idea expresada por SAnto Tomás en Suma Teológica I, q.15, a.3, ad.1 Por eso en Dios no hay idea del mal ni como ejemplar ni como razón. Cf. Suma Teológica en su versión online http://hjg.com.ar/sumat/a/c15.html tomada en internet el 3 de febrero de 2019.

31 «La relación posible-real se invierte en el plano del Mal,; porque mientras que para el Bien lo real es superior a lo posible, para el Mal está por debajo de lo posible. El Bien como posible es lo imperfecto, como realidad lo perfecto. Pero el Mal como posible vale más que como realidad». Pentzopoulou-Valalas, Th., "Kierkegaard et Socrate ou Socrate vu par Kierkegaard». En Les études philosophiques, abril-junio 1979, p. 162.

32 SKS 9, 286, Kjerlighedens Gjerninger. Las obras del amor. 
como si el Cristo no quisiera que nosotros viéramos en su escarnio motivo de sufrimiento, como si el Cristo no quisiera ser reconocido como mártir. ¿Podría soportar el individuo tener conciencia del mal que se está realizando en ese momento con el Cristo? La fe puede que llegue a su máxima pureza cuando da, de alguna manera, ese paso. ¿Qué hace, entonces, Dios?

Sin embargo, hay para Dios un obstáculo: él se lo ha puesto a sí mismo. Sí, amorosamente, por un incomprensible amor, él se lo ha puesto. Porque él lo ha puesto y lo pone cada vez que un hombre nace, el cual, en su amor, lo hace ser algo enfrente de él. ¡Oh maravilla de la omnipotencia y del amor! Un hombre, él no puede sufrir que sus «criaturas» sean algo justo enfrente de él. Ellas deben ser nada y es por lo que él las llama, y con desprecio, sus «criaturas». Pero Dios, que crea de la nada, en su omnipotencia tira de la nada y dice: «Sea», y añade: "Sea algo enfrente mía». ¡Amor maravilloso! Así la omnipotencia de Dios es el poder del amor! ${ }^{33}$

Y saca las consecuencias de esta manera de crear:

Si Dios fuera exclusivamente el Omnipotente, él no tendría ninguna interdependencia; porque la creación no es nada para la Omnipotencia. Pero ella (la creación) es algo para el amor. Incomprensible omnipotencia del amor. [...] La omnipotencia, que crea de la nada, es menos incomprensible que el amor omnipotente que, de esta nada miserable para la omnipotencia, hace algo para el amor. ${ }^{34}$

Dios se ha auto-limitado, se ha retraído por amor. Algo hemos apuntado en el punto anterior. Dios ha querido que su amor sea más importante que su omnipotencia. Su creación es una creación amorosa. Por ello, crea algo que tiene vida propia. La interdependencia es una categoría de la libertad, aunque la criatura se pueda perder, se vaya y se aleje de Dios. Éste se retira para dejar que la criatura sea suya, de sí misma. No debemos olvidar que es el amor el que está en la base y la actuación de Dios. Y ese Amor, incomprensible para el individuo que no es inocente, es más misterioso que su omnipotencia. Ese amor puede pedirle al ser humano cualquier cosa y este puede, o no, dársela. De lo contrario, la relación no sería de interdependencia libre, sino una relación de dependencia para seguir vivo.

El amor paciente de Dios es nuestra salvación, dice la Sagrada Escritura en 2Pe 3, 15. La paciencia de Dios es la que genera la libertad del ser humano. El Amor de Dios nos acompaña siempre en el camino de la vida. El ser humano puede ser enseñado a amar y a tener paciencia. El amor es la mejor arma contra el mal que quiere hacernos malos. La paciencia nos ayuda a no desesperar ante el misterio del mal. Amar hace que lo malo del mal vaya teniendo menos poder.

33 SKS 10, 138, Christelige Taler. Discursos cristianos.

34 SKS 10, 138.139, Christelige Taler. Discursos cristianos. 


\section{BiBLIOGRAFÍA BÁSICA}

Chalier, C. (2016). La gravité de l'amour. Philosophie et spiritualité juives. Presses Universitaires de France.

Dalferth, I. (2017). Trascendencia y mundo secular. Ediciones Sígueme.

Dalferth, I. (2018). El mal. Un ensayo sobre el modo de pensar lo inconcebible. Ediciones Sígueme.

García-Baró, M. (1993). Ensayos sobre lo absoluto. Caparrós Editores.

García-Baró, M. (2006). Del dolor, la verdad y el bien. Sígueme.

Garrigues, J.-M. (2016). Dieu sans idée du mal. Méditations sur la miséricorde, Éditions Ad solem, $3^{\text {a }}$ edición revisada y aumentada.

Kierkegaard, S. (1997-2013). Søren Kierkegaards Skrifter. Gads Forlag3.

Legarreta Bilbao, N. (2013). Método y objeto en la autoría de Kierkegaard o el arte de pescar con señuelos de pluma. Universidad Pontifica Comillas.

Neiman S. (2012). El mal en el pensamiento moderno. Una historia no convencional de la filosofía. Fondo Cultura económica.

Pentzopoulou-Valalas, Th. (1979). «Kierkegaard et Socrate ou Socrate vu par Kierkegaard». Les études philosophiques, abril-junio 1979, pp. 151-162.

Torralba Roselló, F. (1993).Amor y diferencia. El misterio de Dios en Kierkegaard. Ed. PPU.

Wahl, J. (1938). Études Kierkegaardiennes. Éditions Fernand Aubier.

Universidad Loyola Andalucía

ÁNGEL VIÑAS VERA

avinas@uloyola.es

[Artículo aprobado para publicación en febrero de 2020] 